\title{
Ultrasonographic Evaluation of Equine Fetal Growth Throughout Gestation in Normal Mares Using a Convex Transducer
}

\author{
Harutaka MURASE ${ }^{1)}$, Yoshiro ENDO'), Takeru TSUCHIYA ${ }^{3)}$, Yasumitsu KOTOYORI ${ }^{4)}$, Mitsumori SHIKICHI), \\ Katsumi ITO $^{5)}$, Fumio $\mathrm{SATO}^{1)}$ and Yasuo NAMBO ${ }^{1) *}$ \\ 1)Equine Science Division, Hidaka Training and Research Center, Japan Racing Association, 535-13 Nishicha, Urakawa-cho, \\ Urakawa-gun, Hokkaido 057-0171, Japan \\ 2) Miyazaki Training Farm, Japan Racing Association, 2347 Oharu, Hanagashima-cho, Miyazaki-shi, Miyazaki, 880-0036, Japan \\ 3) Oiwake Farm, 1233-1 Kohyo, Oiwake, Abira-cho, Yuhfutsu-gun, 059-1984, Japan \\ ${ }^{4)}$ Laboratory of Clinical Science and Pathobiology, Equine Research Institute, Japan Racing Association, 321-4 Tokami-cho, \\ Utsunomiya, Tochigi, 320-0856, Japan \\ ${ }^{5)}$ Hidaka Horse Breeders Association, 2-4-4 Tsukiji, Urakawa-cho, Urakawa-gun, Hokkaido 057-0024, Japan
}

(Received 20 May 2013/Accepted 7 March 2014/Published online in J-STAGE 24 March 2014)

ABSTRACT. It has not been common to perform regular ultrasound examination of the fetus in equine practice, due to the increasing volume of the uterus caused by fetal development. The convex three-dimensional transducer is bulb-shaped and is able to observe wide areas. In addition, its operation is simple, making it easy to create appropriate angles for various indices using a transrectal approach. The aim of this study was to measure Thoroughbred fetal growth indices throughout gestation using a convex transducer and to clarify the detectable period of some indices for clinical use. We demonstrated changes in fetal indices, such as crown rump length (CRL), fetal heart rate (FHR), fetal eye and kidney and the combined thickness of uterus and placenta (CTUP). CTUP increased from 30 weeks of gestation, and FHR peaked at 8 weeks and then decreased to term. CRL could be observed until 13 weeks due to its wide angle, longer than in previous reports. Fetal eye and kidney could be observed from 10 and 28 weeks, respectively, and these increased with pregnancy progress. The present results showed the advantage of transrectal examination using a convex transducer for evaluation of normal fetal development. Although ultrasonographic examination in mid- to late-gestation is not common in equine reproductive practice, our comprehensive results would be a useful basis for equine pregnancy examination.

KEY WORDS: convex transducer, fetal growth, thoroughbred, ultrasound.

doi: 10.1292/jvms.13-0259; J. Vet. Med. Sci. 76(7): 947-953, 2014

Pregnancy loss in mares is one of the main factors that reduces reproductive efficacy. Previous studies have revealed cumulative seasonal pregnancy rates of $85-92 \%[8,9]$ and foaling rates of only $69-79 \%[2,8,9]$, suggesting that preventing pregnancy loss and subsequent abortion are important for improving the foaling rate in equine reproduction. Fetal stresses and insults resulting from placental incompetence are cumulative. Cellular damage and derangements of endocrine, metabolic and cardiovascular processes over time produce a syndrome described as intrauterine growth retardation (IUGR) [24]. Three periparturient events that have the most devastating effect on foal survival are hypoxia, infection and derangement of in utero development [40]. Periparturient monitoring should focus on detection of these events to permit timely prepartum therapy for the mare and to ensure attended delivery and early evaluation of the foal [40]. Ultrasonography of the equine pregnancy in advanced

*Correspondence to (Present Address): Nambo, Y., Department of Clinical Veterinary Science, Obihiro University of Agriculture \& Veterinary Medicine, Inada, Obihiro, Hokkaido 080-8555, Japan. e-mail: ynambo@obihiro.ac.jp

(C)2014 The Japanese Society of Veterinary Science

This is an open-access article distributed under the terms of the Creative Commons Attribution Non-Commercial No Derivatives (by-nc-nd) License $<$ http://creativecommons.org/licenses/by-nc-nd/3.0/>. gestation is a discipline of relatively recent acquisition [10]. Furthermore, most of the initial studies were confined to the late gestational mare, and there is a relative paucity of data on assessment of the equine fetus at different stages of development [10]. For example, the diagnosis and treatment of ascending placentitis, which is one of the major causes of equine infectious abortion $[14,18]$, have recently been researched [4, 20, 21, 25]. Ultrasonography is an excellent tool for monitoring fetal and placental changes in mares affected by placentitis [37]. Subclinical disease may also result in subtle ultrasonographic changes. Thus, early intervention in placental infections is likely the key to treatment success [37].

In pregnant women, it is common to perform regular ultrasound examinations throughout the gestational period. Fetal growth is evaluated by crown rump length in early gestation and biparietal diameter, head circumference, abdominal circumference or femoral diaphysis length in late gestation [12]. Fetal well-being is also evaluated by fetal heart rate, amniotic fluid volume or umbilical arterial blood flow using ultrasound [23, 27, 36, 38]. In horses, transrectal ultrasonography is commonly performed at 2-3 weeks after ovulation for pregnancy check and at 5-6 weeks for early embryo loss check. However, subsequent regular ultrasonographic examination is not common. Assessing fetal development during later gestation may also be a valuable tool for identifying foals at increased risk of perinatal disease [11]. 
In this respect, the equine fetus can be examined transabdominally throughout the latter two-thirds of gestation with a low-frequency transducer $(2-3.5 \mathrm{kHz})[29,32,34]$. Previous studies have provided fetal growth data in Thoroughbreds, Quarter horses, Standardbreds and Shetland ponies at 4-11 months of gestation via measurements of the fetal eye orbits, cranium, abdomen, thoracic width, intercostal spaces and aorta [11, 32-34, 39]. However, Hendriks et al. [17] noted large variability in previous reports, because of the relatively low number of animals examined, long inter-examination intervals and absence of serial examinations of individual fetuses. In addition, it may also reflect considerable differences in fetal growth among mares of different breeds, age, size and parity, as these factors significantly influence foal birth weight $[3,28,39,41]$. A plateau in the growth of various fetal parts and considerable variations in fetal size during the last 1-2 months of gestation limit the utility of many ultrasonographic parameters for assessing fetal development [17].

On the other hand, we succeeded in creating three-dimensional (3D) ultrasound images for the first time in equine reproduction [19]. Unlike conventional linear transducers, the convex transducer used in 3D ultrasound examinations in the previous report is bulb-shaped and was able to observe a wide area, particularly in the cranial direction, with regard to both angle (60 degrees) and depth $(30 \mathrm{~cm})$ without discomfort to the mare. Thus, we concluded that using a convex transducer via the transrectal approach is the most suitable procedure for imaging of the equine fetus during the first half of gestation. In addition, it is very easy to control angle in the rectum because of its shape and to obtain cranial views, whereas a linear transducer can only provide ventral views. The aim of this study was to measure Thoroughbred fetal growth indices throughout the whole of gestation using a convex transducer and to refer to the detectable period of some indices for clinical use.

\section{MATERIALS AND METHODS}

Animals: In 2010 and 2011, a total of 16 pregnancies (in 10 healthy Thoroughbred mares) were examined. Mares were aged $9.4 \pm 3.9$ years (range; $4-15$ years). Parity of the mares was $4.4 \pm 3.3$ (range; $0-9$ ). Three of the mares were primiparous, i.e., carrying their first foal. Pregnancy period was 343 \pm 6.9 days (range; $331-355$ days). Mares were stabled at the JRA Hidaka training and research center (Urakawa, Japan). They were fed to maintain body condition scores of 6.0 to 7.0. Their diet included alfalfa, timothy, oats and permanent pasture during summer, and they were housed individually at night and compound feed was given as required during winter. All mares foaled as scheduled with no abnormalities detected in any foal. This study was approved by the Animal Care and Use Committee at Hidaka Training and Research Center.

Ultrasound examination: Mares were examined by transrectal ultrasound and were subsequently examined via a transabdominal approach. Ultrasonography was performed using a Prosound $\alpha 7$ (Hitachi Aloka Medical, Ltd., Tokyo, Japan) with frequency variability. For the transrectal ap-

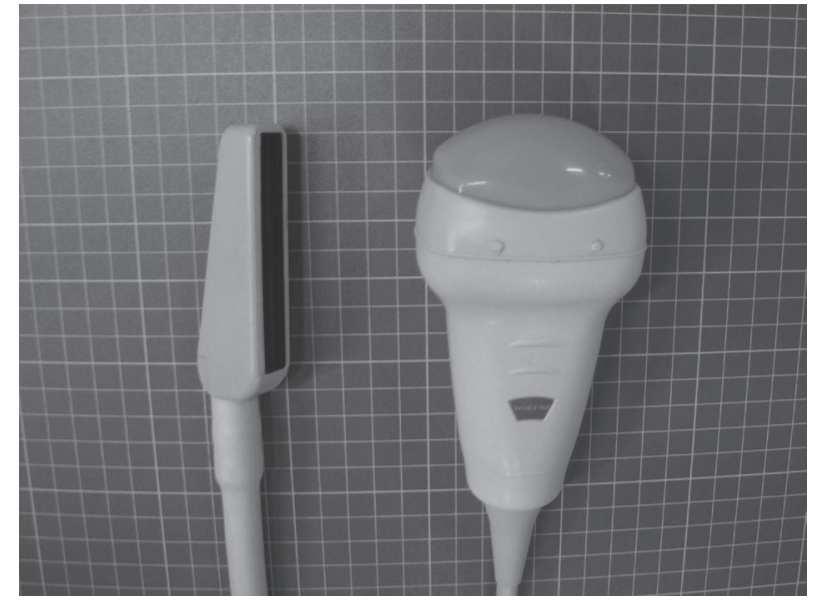

Fig. 1. Appearance of transducers. The convex transducer is able to image at up to $30 \mathrm{~cm}$ depth and can readily be operated in mare's rectum, because of its form.

proach, a linear transducer (UST-5821-7.5; 4-13 MHz; maximum depth, $15 \mathrm{~cm}$ ) set at $8.0 \mathrm{MHz}$ and a convex transducer (ASU-1010; 2-10 MHz; maximum depth, $30 \mathrm{~cm}$ ) set at 8.0 $\mathrm{MHz}$ were used. For the transabdominal approach, a convex transducer which was set at 5.0 or $8.0 \mathrm{MHz}$ was used (Fig. 1). The transducer and frequency depended on fetal size. The linear transducer imaged to a depth of $15 \mathrm{~cm}$ and width of $60 \mathrm{~mm}$, while the convex transducer imaged to a depth of $30 \mathrm{~cm}$, a radius of $40 \mathrm{~mm}$, and an angle of 60 degrees. Prior to transabdominal ultrasound, hair was removed from the ventral abdominal mid-line from the mammary glands to the xiphoid sternum, as appropriate. Mares were examined every week between 2 and 22 weeks of gestation and were then examined every other week until delivery. The duration of ultrasound examination varied from 15 to $30 \mathrm{~min}$, depending on fetal position, presentation, posture and pregnancy period. All indicators were measured 2 or more times and were then standardized as means. All data in this study were obtained by the same person.

Combined Thickness of Uterus and Placenta (CTUP): Transrectal measurements of the CTUP were obtained at the ventral aspect of the cervical pole, as described by Renaudin et al. [35]. We measured at least three regions and calculated mean values for each examination (Fig. 2A).

Fetal Heart Rate (FHR): FHR was examined in the heart or arteries using Doppler mode. Because fetal activity resulted in acceleration in FHR $[1,11]$, we adopted the lowest value as FHR.

Crown Rump Length (CRL): CRL was measured transrectally. The convex transducer was rotated in the rectum such that the key axis view of the fetus which means the neck or body was straight, not lateral bending could be visualized (Fig. 2B).

Fetal eye orbit: Fetal eye orbits were mainly imaged transrectally. All measurements were performed at the maximum orbital cross-section, using the lens capsule and inner margins of the vitreous body as landmarks. Eye width was cal- 


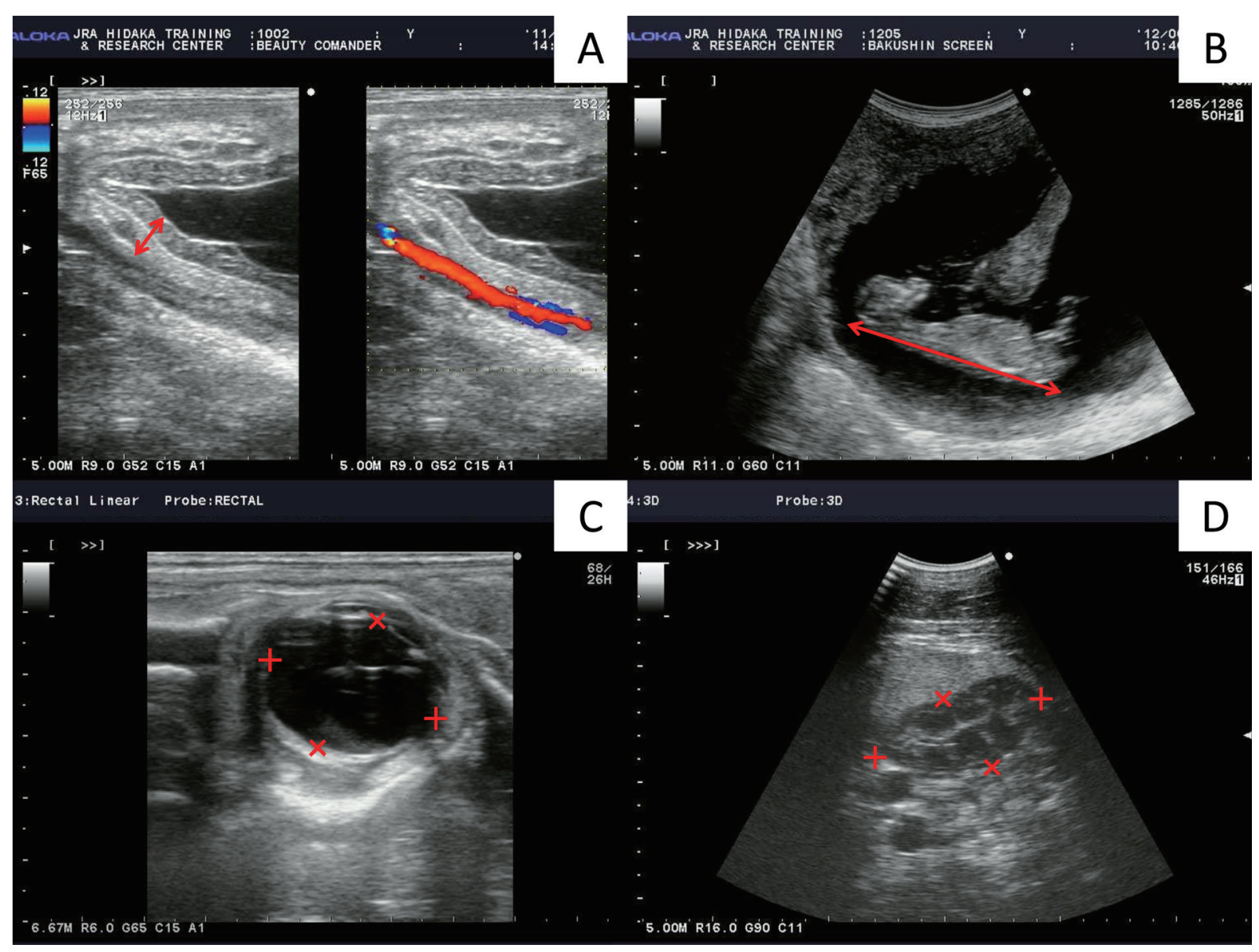

Fig. 2. Measurement of ultrasonographic indices of pregnant mare. (A) Transrectal images in the ventral part of the uterine body, near the cervix. Headers show the combined thickness of the uterus and placenta (CTUP). (B) Transrectal image of Crown Rump Length (CRL) (header). (C) Transrectal image of fetal eye orbit. Eye length $(+)$ and width $(\times)$ measurements are shown. Eye length is measured from the maximum length of the inner margins of the vitreous body, and eye width is measured from the margin of the anterior portion of the capsule of the lens to the inner margin of the optic disc. (D) Transabdominal image of the fetal abdomen at the level of the kidney. Kidney cross-sectional length $(+)$ and width $(\times)$ measurements are shown.

lipered from the margin of the anterior portion of the capsule of the lens to the inner margin of the optic disc. Eye length perpendicular to the eye width was then measured from the maximum length of the inner margins of the vitreous body (Fig. 2C). We recorded the length and width and calculated the approximate volume (length $\times$ length $\times$ width), as described by Renaudin et al. [34].

Fetal kidney: Kidneys were observed in cross section transabdominally with anterior presentation and transrectally with posterior presentation. The image was frozen when the maximal cross sectional area of the kidney was obtained. We recorded the length and width (Fig. 2D) and calculated the approximate area (length $\times$ width), as described by Renaudin et al. [34].

Detection rate: We calculated the detection rate for particular organs as the number in which indices could be measured divided by the total number at each time point. Rates over $50 \%$ were defined as positive for detection. In addition, the approach was categorized into three cases; could be measured with transrectally a linear transducer, could be measured transrectally with a convex transducer and could be measured transabdominally with a convex transducer.

Statistical analysis: Results are expressed as means \pm standard error of the mean (SEM). Data were analyzed by one-way ANOVA followed by Tukey's HSD test for multiple comparisons. Statistical analyses were performed using JMP software (SAS Institute Japan Inc., Tokyo, Japan). Significance was established at $P<0.05$.

\section{RESULTS}

The value of CTUP remained steady until 28 weeks of gestation, increased until term and reached $9.4 \pm 1.3 \mathrm{~mm}$ at term (48 weeks) (Fig. 3A). CTUPs after 38 weeks were significantly higher than those before 28 weeks $(P<0.05)$. The echoic view of CTUP showed a bilayer structure with placental development (Fig. 2A).

FHR could be measured from 4 weeks of gestation. FHR 

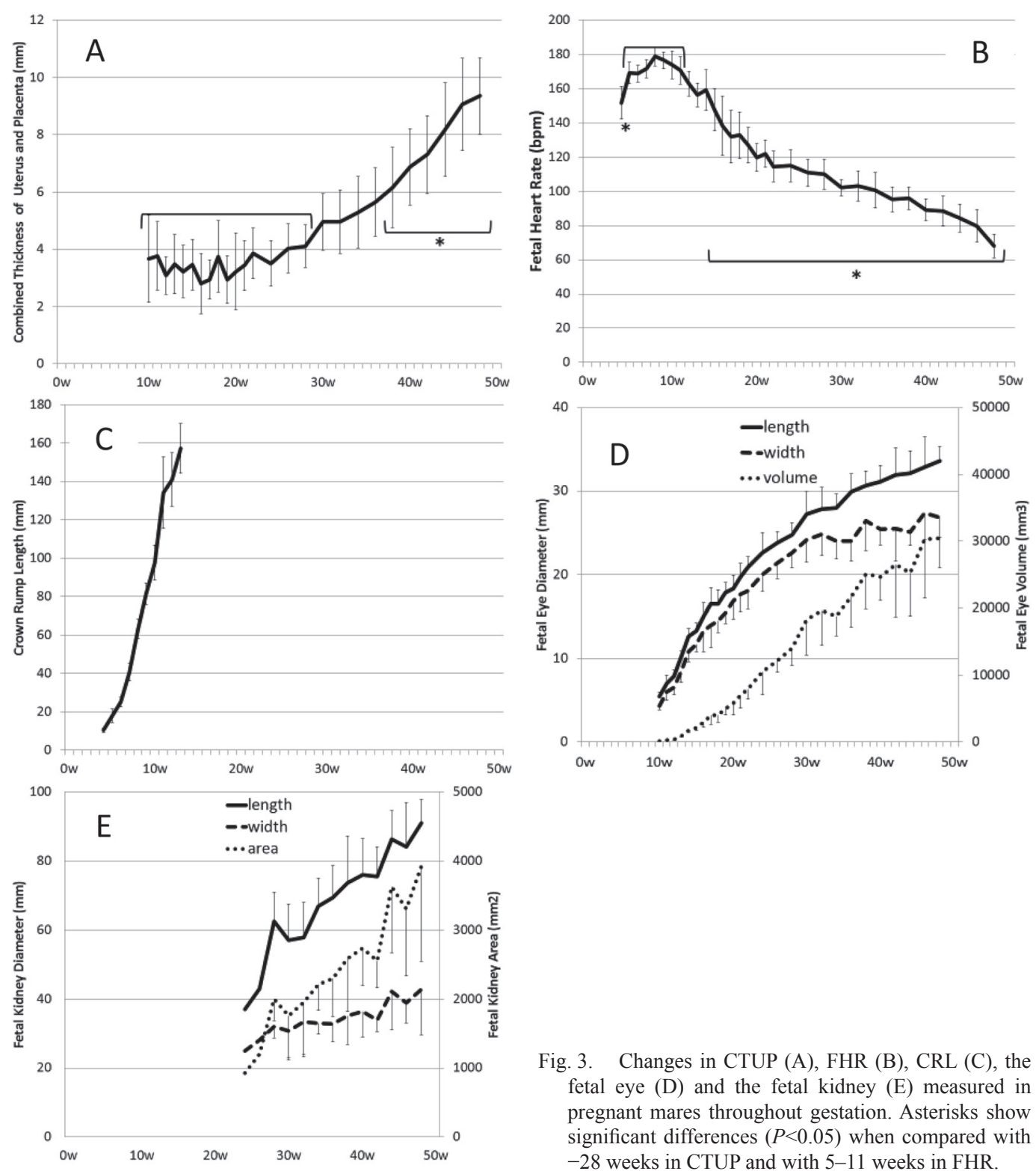

was $151.7 \pm 9.5 \mathrm{bpm}$ at 4 weeks and peaked $178.8 \pm 5.7 \mathrm{bpm}$ at 8 weeks, before decreasing gradually toward $68.0 \pm 7.0 \mathrm{bpm}$ at term (48 weeks) (Fig. 3B). FHR values at 4 weeks and after 15 weeks were significantly lower than those between 5 and 11 weeks $(P<0.05)$. Using the transrectal approach, we were able to perform measurements using the linear transducer until 9 weeks and were subsequently able to use the convex transducer between 10 and 32 weeks (Fig. 4).

CRL increased linearly from $18.0 \pm 3.5 \mathrm{~mm}$ at 5 weeks of gestation to $157.4 \pm 13.0 \mathrm{~mm}$ at 13 weeks, but the detection rate decreased rapidly after 10 weeks and was not detected after 14 weeks due to a lateral bending of the neck or body (Figs. 3C and 4). Up to 6 weeks, detection was possible with the linear transducer, but not after 7 weeks (Fig. 4).

Fig. 3. Changes in CTUP (A), FHR (B), CRL (C), the fetal eye (D) and the fetal kidney (E) measured in pregnant mares throughout gestation. Asterisks show significant differences $(P<0.05)$ when compared with -28 weeks in CTUP and with 5-11 weeks in FHR.

Fetal eye diameter increased with gestational age. The increases in width, length and area were similar (Fig. 3D). Detection rate of eye was maintained between 60 and $90 \%$ after 10 weeks (Fig. 4). Using the transrectal approach, detection was only possible between 15 and 17 weeks and after 44 weeks with the linear transducer. However, detection was possible throughout gestation with the convex transducer.

The fetal kidney was detected transabdominally from 28 weeks of gestation, and the value increased linearly (Fig. 3E). Detection rate was 60-90\% throughout gestation, depending on fetal position (Fig. 4). When fetal position was dorsoventral or dorsosacral, it was difficult to observe fetal kidneys. 


\section{Detectable Periods}

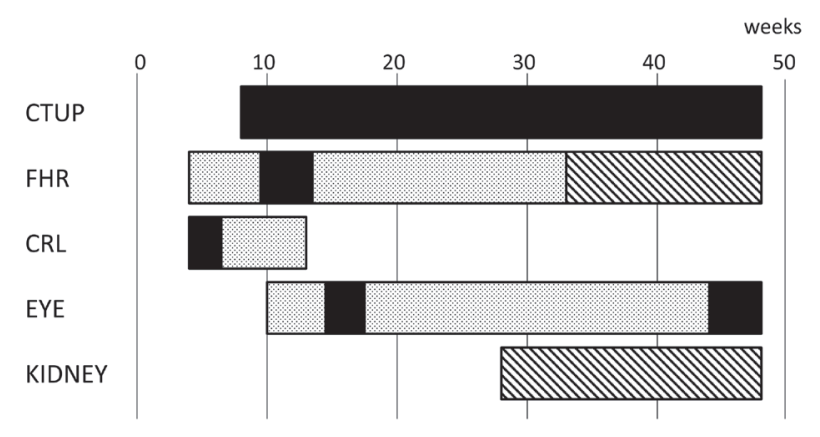

Fig. 4. Detectable periods for each index in pregnant mares. Bars show when the detection rates are over $50 \%$. $\square$ : transrectal approach with linear transducer. : : : transrectal approach with convex transducer. IIII: transabdominal approach with convex transducer.

\section{DISCUSSION}

The present study demonstrated the advantages of both transrectal and transabdominal examinations using a convex transducer for evaluation of fetal components, such as CRL, eye orbit, kidney and heart, in pregnant mares during particular periods of gestation. In addition, the benefits of CTUP measurement can be confirmed using a conventional linear transducer for evaluation of normal development of the placenta, as reported previously by Renaudin et al. [35] throughout the gestational period in pregnant Thoroughbred mares. We measured the same Thoroughbred mares in series in this study. Although ultrasonographic examination in pregnant mares is not presently common in equine reproductive practice, our comprehensive results would be a basis for equine pregnancy examination.

Recently, CTUP has become more widely used as an indicator of placentitis. The $95 \%$ upper confidence limit is a plateau of about $4 \mathrm{~mm}$ by 9 months of gestation, followed by an increase of 1.5-2.0 mm every month, reaching $12 \mathrm{~mm}$ in the last month in some breeds [35]. Another report indicated no changes by 200 days, followed by a rapid increase from 250 days to term and a $95 \%$ upper confidence limit of $12.1 \mathrm{~mm}$ in primiparous and $12.6 \mathrm{~mm}$ in multiparous mares in the last period of gestation in Dutch Warmbloods [17]. These data were similar to those of the present study showing a $95 \%$ upper confidence limit of $11.2 \mathrm{~mm}(8.59 \pm 1.29 \mathrm{~mm})$ in 11 multiparous Thoroughbred mares at term, despite the CTUP data being obtained in different breeds.

Several reports have investigated FHR in late gestation $[1,33]$ or middle gestation [11, 17]. Hendriks et al. [17] reported that it was approximately $145 \mathrm{bpm}$ at 100 days and $75 \mathrm{bpm}$ at term in Dutch Warmbloods transabdominally. Bucca et al. [11] also reported it at rest transabdominally and transrectally, and the results were approximately 115 , $110,105,90,85,75$ and $65 \mathrm{bpm}$ at rest at 6-12 months of gestation (breeds not shown). Our results showed that FHR could be measured using a linear transducer until 9 weeks and could not be subsequently measured because fetal position moved ventrally and cranially.

Hendriks et al. [17] showed a linear approximation formula after 100 days, but our results did not show a linear formula; the decrease was initially larger, then smaller in the middle gestation period and larger again before delivery. Our results were similar to those measured previously by Bucca et al. at rest [11] (Fig. 3C). As in humans, episodes of FHR variability in equine fetuses (accelerations and decelerations) increase in frequency as gestation progresses, and transient $(15-30 \mathrm{sec})$ acceleration usually coincides with periods of fetal activity $[1,11]$. Thus, we repeated measurements several times and adopted the lowest scores, rather than mean scores. Persistent bradycardia or tachycardia is generally an indication of fetal stress, where bradycardia is often a result of central nervous system depression due to hypoxia $[5,11]$, and has been associated with a poor outcome in humans [16] and pregnant mares [1]. When abnormal FHR was detected, fetomaternal electrocardiography, which is capable of successive monitoring, may be useful $[22,26]$.

There are few original reports on equine fetal CRL based on a gross anatomical study $[6,7,13]$. These data have been used to estimate fetal age. Previous reports have presented ultrasonographic data of CRL up to 55 days of gestation transrectally, but it is difficult to place a linear transducer in a true longitudinal orientation with respect to the fetus [15]. The convex transducer we used was bulb-shaped and was therefore easy to control in the rectum, in contrast to conventional linear transducers. We were able to measure CRL until 6 weeks using linear transducer, but could not place the transducer in a correct longitudinal orientation after 7 weeks. Using convex transducer, the CRL was measured CRL up to 13 weeks. After 10 weeks, lateral bending of the neck or body made further measurement impossible. Our results were consistent with previous ultrasonography data before 55 days [15] and with actual measurements taken before 14 weeks $[6,13]$.

Fetal eye orbit initially has a globular shape, but it develops into an orbital shape, in which the width is smaller than the length. Previous studies have used the sum of two diameters (length and width) of the orbit [11], approximate volume (width $\times$ length $\times$ length) [34] or length alone [39]. Turner et al. [39] compared the length, width and the ratio of length to width and concluded that the length is the best single predictor of days before parturition in small ponies. This result also means that the eye length is a better predictor of fetal size than the width or ratio of length to width. Our results also suggested the usefulness of eye length alone, because the increase in length with gestational age is larger than that in width. One previous report showed linear increases in the sum of two diameters [11], but another showed a plateau beginning at about 9 months of gestation [39]. Renaudin et al. [34] suggested that approximate eye volume was also the only eye parameter that had a linear relationship with time. It was difficult using our procedure to image the entire width of the eye, resulting in variations in scores. Approximate eye volume in our results showed linear increases in late 
gestation, but showed exponential increases in early gestation. This may be because eye orbital shape changes from a globular into a convex shape (the increase in width is smaller than that in length). Fetal eyes could be readily examined until 16 weeks, but were then maintained at $60-90 \%$. The main reasons for failed examination were posterior presentation at 17-26 weeks and neck bending or forelimb extension with anterior presentation after 28 weeks. Imaging with the linear transducer was only possible between 15 and 17 weeks and from 44 weeks to term. During other periods, observation of fetal eye orbit required the convex transducer, as the fetal head was positioned in the cranial-ventral direction.

The fetal kidney was easily detected transabdominally, but there have been few reports on this issue [34]. Renal shape was amorphous, and the visualized shape varied depending on the angle of the transducer. However, it could be measured in cross-section by using ribs as landmarks. Renaudin et al. [34] measured renal length, width and cross section area (length $\times$ width) and determined the linear relationship between the cross-section area and day of gestation. Increases in the length and width of the kidney had a linear relationship with weeks of gestation, resulting in an exponential increase in cross-sectional area (length $\times$ width) in the present study. The present data were supported by previous reports noting that kidney weight relative to fetal body weight was approximately $10 \%$ at $4-5$ months, $7-8 \%$ in each subsequent month and $6.6 \%$ at birth [31]. The fetal kidney was detected frequently $(>60 \%)$ between about 30 weeks and term; thus, it may be a useful index of fetal growth. At near term, detection rate decreased, because fetal lumbar was situated on the maternal xiphoid sternum based on fetal development.

Previous reports have shown a plateau in the eye orbital diameter and biparietal diameter in late gestation [17, 39]. The greatest increase in CRL occurs in mid-gestation, although weight gain increases to a maximum near term [30]. CRL reflects the growth of the head and the vertebral column, and weight is mainly determined by the developing muscles and other soft tissues [30]. It is clear that the developmental stages of organs are different [31]. For example, organs, such as the heart, liver and kidney, showed greatest relative development at 4-5 months of gestation, while the spleen peaks at 8-9 months [31]. Therefore, establishment of developmental curves for each anatomical part and organ in the fetus may be useful for clinical applications of ultrasonography. Moreover, it will be important to understand the gestational periods when each index can be observed and the detectable rates for quantitative evaluation.

From the present study, we concluded that transrectal ultrasonographic examination to assess the development of fetal components using a convex transducer is very useful from the view point of operability, particularly in the cranial direction. FHR and eye orbit were observed throughout gestation transrectally using a convex transducer, whereas only limited periods of observation were possible with the linear transducer. The present results also suggested that fetal development should be evaluated using several parameters, during suitable periods of gestation, e.g., CRL during the first trimester, eye orbit during the second trimester and kidney and CTUP during the third trimester of gestation in mares. This new method should be added to assess fetal development in high-risk pregnant mares in order to widen the diagnostic window and also contributes to effective monitoring, such as early diagnosis, early treatment or treatment evaluation. In practice, high-risk mares should be subjected to regular monitoring with the transrectal approach, measuring FHR, CRL, eye diameter or fetal activity after 6 months of gestation, when the abortion rate increases [18], except in mares that already show clinical findings. If findings, such as blood hormone levels, clinical findings or prolonged gestational period, are observed, the transabdominal approach should be added for advanced monitoring.

\section{REFERENCES}

1. Adams-Brendemuehl, C. and Pipers, F. S. 1987. Antepartum evaluations of the equine fetus. J. Reprod. Fertil. Suppl. 35: 565-573. [Medline]

2. Allen, W. R., Brown, L., Wright, M. and Wilsher, S. 2007. Reproductive efficiency of Flatrace and National Hunt Thoroughbred mares and stallions in England. Equine Vet. J. 39: 438-445. [Medline] [CrossRef]

3. Allen, W. R., Wilsher, S., Turnbull, C., Stewart, F., Ousey, J., Rossdale, P. D. and Fowden, A. L. 2002. Influence of maternal size on placental, fetal and postnatal growth in the horse. I. Development in utero. Reproduction 123: 445-453. [Medline] [CrossRef]

4. Bailey, C. S., Macpherson, M. L., Pozor, M. A., Troedsson, M. H., Benson, S., Giguere, S., Sanchez, L. C., Leblanc, M. M. and Vickroy, T. W. 2010. Treatment efficacy of trimethoprim sulfamethoxazole, pentoxifylline and altrenogest in experimentally induced equine placentitis. Theriogenology 74: 402-412. [Medline] [CrossRef]

5. Baschat, A. A. and Hecher, K. 2004. Fetal growth restriction due to placental disease. Semin. Perinatol. 28: 67-80. [Medline] [CrossRef]

6. Bergin, W. C., Gier, H. T., Frey, R. A. and Marion, G. B. 1967, Developmental horizons and measurements useful for age determination of equine embryos and fetuses. pp. 179-196. In: Annual Convnention of American Association of Equine Practitioners. New Orleans.

7. Betteridge, K. J., Eaglesome, M. D., Mitchell, D., Flood, P. F. and Beriault, R. 1982. Development of horse embryos up to twenty two days after ovulation: observations on fresh specimens. J. Anat. 135: 191-209. [Medline]

8. Bosh, K. A., Powell, D., Neibergs, J. S., Shelton, B. and Zent, W. 2009. Impact of reproductive efficiency over time and mare financial value on economic returns among Thoroughbred mares in central Kentucky. Equine Vet. J. 41: 889-894. [Medline] [CrossRef]

9. Brück, I., Anderson, G. A. and Hyland, J. H. 1993. Reproductive performance of thoroughbred mares on six commercial stud farms. Aust. Vet. J. 70: 299-303. [Medline] [CrossRef]

10. Bucca, S. 2011. Ultrasonographic monitoring of the fetus. pp. 39-54. In: Equine Reproduction, vol 1, 2nd ed. (McKinnon, A. O., Squires, E. L., Vaala, W. E. and Varner, D. D. eds.), WileyBlackwell, Ames.

11. Bucca, S., Fogarty, U., Collins, A. and Small, V. 2005. Assessment of feto-placental well-being in the mare from mid-gestation to term: transrectal and transabdominal ultrasonographic features. Theriogenology 64: 542-557. [Medline] [CrossRef] 
12. Cullinan, J. A., Hertzberg, B. S. and Lee, W. 2003. AIUM Practice Guideline for the performance of an antepartum obstetric ultrasound examination. J. Ultrasound Med. 22: 1116-1125. [Medline]

13. Evans, H. E. and Sack, W. O. 1973. Prenatal development of domestic and laboratory mammals: growth curves, external features and selected references. Zentralbl. Veterinarmed. $[C] \mathbf{2}$ : 11-45. [Medline]

14. Giles, R. C., Donahue, J. M., Hong, C. B., Tuttle, P. A., PetritesMurphy, M. B., Poonacha, K. B., Roberts, A. W., Tramontin, R. R., Smith, B. and Swerczek, T. W. 1993. Causes of abortion, stillbirth, and perinatal death in horses: 3,527 cases (1986-1991). J. Am. Vet. Med. Assoc. 203: 1170-1175. [Medline]

15. Ginther, O. J. 1995. Ultrasonic Imaging and Animal Reproduction, Equiservices Publishing, Cross Plains.

16. Grubb, D. K. and Paul, R. H. 1992. Amniotic fluid index and prolonged antepartum fetal heart rate decelerations. Obstet. Gynecol. 79: 558-560. [Medline]

17. Hendriks, W. K., Colenbrander, B., van der Weijden, G. C. and Stout, T. A. 2009. Maternal age and parity influence ultrasonographic measurements of fetal growth in Dutch Warmblood mares. Anim. Reprod. Sci. 115: 110-123. [Medline] [CrossRef]

18. Hong, C. B., Donahue, J. M., Giles, R. C. Jr., Petrites-Murphy, M. B., Poonacha, K. B., Roberts, A. W., Smith, B. J., Tramontin, R. R., Tuttle, P. A. and Swerczek, T. W. 1993. Equine abortion and stillbirth in central Kentucky during 1988 and 1989 foaling seasons. J. Vet. Diagn. Invest. 5: 560-566. [Medline] [CrossRef]

19. Kotoyori, Y., Yokoo, N., Ito, K., Murase, H., Sato, F., Korosue, K. and Nambo, Y. 2012. Three-dimensional ultrasound imaging of the equine fetus. Theriogenology 77: 1480-1486. [Medline] [CrossRef]

20. Macpherson, M. L. 2005. Treatment strategies for mares with placentitis. Theriogenology 64: 528-534. [Medline] [CrossRef]

21. Macpherson, M. L. and Bailey, C. S. 2008. A clinical approach to managing the mare with placentitis. Theriogenology $\mathbf{7 0}$ : 435-440. [Medline] [CrossRef]

22. Matsui, K., Sugano, S. and Masuyama, I. 1985. Changes in the fetal heart rate of thoroughbred horse through the gestation. Nippon Juigaku Zasshi 47: 597-601. [Medline] [CrossRef]

23. Moore, T. R. and Cayle, J. E. 1990. The amniotic fluid index in normal human pregnancy. Am. J. Obstet. Gynecol. 162: 1168-1173. [Medline] [CrossRef]

24. Morresey, P. R. 2011. The placenta. pp. 84-95. In: Equine Reproduction, vol 1, 2nd ed. (McKinnon, A. O., Squires, E. L., Vaala, W. E. and Varner, D. D. eds.), Wiley-Blackwell, Ames.

25. Morris, S., Kelleman, A. A., Stawicki, R. J., Hansen, P. J., Sheerin, P. C., Sheerin, B. R., Paccamonti, D. L. and LeBlanc, M. M. 2007. Transrectal ultrasonography and plasma progestin profiles identifies feto-placental compromise in mares with experimentally induced placentitis. Theriogenology 67: 681-691. [Medline] [CrossRef]

26. Nagel, C., Aurich, J. and Aurich, C. 2010. Determination of heart rate and heart rate variability in the equine fetus by fetomaternal electrocardiography. Theriogenology 73: 973-983. [Medline]
[CrossRef]

27. Newnham, J. P., Patterson, L. L., James, I. R., Diepeveen, D. A. and Reid, S. E. 1990. An evaluation of the efficacy of Doppler flow velocity waveform analysis as a screening test in pregnancy. Am. J. Obstet. Gynecol. 162: 403-410. [Medline] [CrossRef]

28. Ousey, J. C., Rossdale, P. D., Fowden, A. L., Palmer, L., Turnbull, C. and Allen, W. R. 2004. Effects of manipulating intrauterine growth on post natal adrenocortical development and other parameters of maturity in neonatal foals. Equine Vet. J. 36: 616-621. [Medline] [CrossRef]

29. Pipers, F. S. and Adams-Brendemuehl, C. S. 1984. Techniques and applications of transabdominal ultrasonography in the pregnant mare. J. Am. Vet. Med. Assoc. 185: 766-771. [Medline]

30. Platt, H. 1978. Growth and maturity in the equine fetus. J. R. Soc. Med. 71: 658-661. [Medline]

31. Platt, H. 1984. Growth of the equine foetus. Equine Vet. J. 16: 247-252. [Medline] [CrossRef]

32. Reef, V. B. 1998. Fetal ultrasonography. pp. 425-445. In: Equine Diagnostic Ultrasound (Reef, V. B. ed.), Saunders, Philadelphia.

33. Reef, V. B., Vaala, W. E., Worth, L. T., Spencer, P. A. and Hammett, B. 1995. Ultrasonographic evaluation of the fetus and intrauterine environment in healthy mares during late gestation. Vet. Radiol. Ultrasound 36: 533-541. [CrossRef]

34. Renaudin, C. D., Gillis, C. L., Tarantal, A. F. and Coleman, D. A. 2000. Evaluation of equine fetal growth from day 100 of gestation to parturition by ultrasonography. J. Reprod. Fertil. Suppl. 56 : 651-660. [Medline]

35. Renaudin, C. D., Troedsson, M. H., Gillis, C. L., King, V. L. and Bodena, A. 1997. Ultrasonographic evaluation of the equine placenta by transrectal and transabdominal approach in the normal pregnant mare. Theriogenology 47: 559-573. [Medline] [CrossRef]

36. Stuart, B., Drumm, J., FitzGerald, D. E. and Duignan, N. M. 1980. Fetal blood velocity waveforms in normal pregnancy. $\mathrm{Br}$. J. Obstet. Gynaecol. 87: 780-785. [Medline] [CrossRef]

37. Troedsson, M. H. and Macpherson, M. L. 2011. Placentitis. pp. 2359-2367. In: Equine Reproduction, vol 2, 2nd ed. (McKinnon, A. O., Squires, E. L., Vaala, W. E. and Varner, D. D. eds.), WileyBlackwell, Ames.

38. Trudinger, B. J., Cook, C. M., Giles, W. B., Ng, S., Fong, E., Connelly, A. and Wilcox, W. 1991. Fetal umbilical artery velocity waveforms and subsequent neonatal outcome. Br. J. Obstet. Gynaecol. 98: 378-384. [Medline] [CrossRef]

39. Turner, R. M., McDonnell, S. M., Feit, E. M., Grogan, E. H. and Foglia, R. 2006. Real-time ultrasound measure of the fetal eye (vitreous body) for prediction of parturition date in small ponies. Theriogenology 66: 331-337. [Medline] [CrossRef]

40. Vaala, W. E. 2011. Monitoring the High-Risk Pregnancy. pp. 16-24. In: Equine Reproduction, vol 1, 2nd ed. (McKinnon, A. O., Squires, E. L., Vaala, W. E. and Varner, D. D. eds.), WileyBlackwell, Ames.

41. Wilsher, S. and Allen, W. R. 2002. The influences of maternal size, age and parity on placental and fetal development in the mare. Theriogenology 58: 833-835. [CrossRef] 